\title{
The Effects of Evaporative Cooling in Tropical Climate
}

\author{
Robert Poku*, Tokoni W. Oyinki, Ezenwa A. Ogbonnaya \\ Department of Marine/Mechanical Engineering, Niger Delta University, Wilberforce Island, Bayelsa State, Nigeria \\ *Corresponding author: robertpoku21@gmail.com
}

\begin{abstract}
The performance of thermal power plants, achievement of human comfort, preservation of groceries etc. are generally adversely affected by poor environmental conditions. In order to provide solutions to these challenges, an evaporative cooling system was developed and studied. The study was aimed at providing lower temperatures for the efficient performance of machineries and human comfort as well as lower temperature and higher relative humidity necessary for overcoming the above adverse condition. The performance of the cooler was evaluated in terms of temperature drop, cooler capacity, saturation efficiency and feasibility index. The results showed that evaporative cooling is achievable with feasibility index of $\mathrm{F}^{*} \leq 10$, when the difference between inlet dry bulb temperatures and wet bulb temperature are greater, $\mathrm{T}_{1}-\mathrm{T}_{\mathrm{w}}=11.5^{\circ} \mathrm{C}$ and $\mathrm{T}_{1}-\mathrm{T}_{2}=25.22^{\circ} \mathrm{C}$ with $\mathrm{F}^{*}=9 ; \mathrm{T}_{1}-\mathrm{T}_{\mathrm{w}}=12^{\circ} \mathrm{C}$ and $\mathrm{T}_{1}-\mathrm{T}_{2}=7.109^{\circ} \mathrm{C}$ with $\mathrm{F}^{*}=10$ respectively. The results also affirmed that cooler capacity and the saturation index are higher where the feasibility indexes are comparatively low.
\end{abstract}

Keywords: evaporative cooler, feasibility index, saturation efficiency, cooler capacity

Cite This Article: Robert Poku, Tokoni W. Oyinki, and Ezenwa A. Ogbonnaya, "The Effects of Evaporative Cooling in Tropical Climate." American Journal of Mechanical Engineering, vol. 5, no. 4 (2017): 145-150. doi: 10.12691/ajme-5-4-5.

\section{Introduction}

Evaporative cooling occurs when air, that is not too humid, passes over a wet surface (humidifier). The movement of the air can be passive, that is when the air flows naturally through the pads (wet surface) or active when it is made to flow with fans or blowers [1]. It provides cold air for gas turbine inlet air, buildings cooling and perishables such as vegetables and fruits preservation. It offers an alternative to conventional air conditioners in hot, dry climates with high system efficiency, low initial investment and maintenance. It also has the advantage of providing some level of cooling for a fraction of the energy consumption [2].

According to [3], regions with hot climates, energy for space cooling accounts for over $60 \%$ of the total energy used in buildings. Direct evaporating cooling systems in low humidity zones typically realize an energy savings of 60 to $80 \%$ over refrigerated systems [4]. Reason being that the only power consuming components of an evaporative cooler are fans and water pumps. Energy savings with evaporative cooling vary with humidity levels and temperatures. It is also an environmentally friendly and energy efficient cooling method that only uses water as the working fluid [4].

Physiological factors such as respiration involve heat emission resulting in increase of temperature, and this produces metabolic process and decay [5]. Generally, the loss of freshness of perishable commodities depends on the rate of respiration in the storage space [6]. And this results to rise in temperature. Evaporative cooling therefore becomes an efficient and economical means for reducing the temperature and increasing the relative humidity in a storage space. This effect has been extensively tried for increasing good shelf-life of vegetables.

Extending the shell-life of vegetables and fruits, several authors have recommended the proper storage of these products at lower temperatures. Proper storage means controlling both the temperature and relative humidity of the storage space [7]. Reason being that the storage of vegetable crops is one which requires high relative humidity and low air temperature. Evaporative cooling device will allow for the appropriate cooling temperatures of between $0^{\circ} \mathrm{C}$ to $21^{\circ} \mathrm{C}$ [8] necessary to reduce deterioration process.

The performance of gas turbine plants generally, are temperature dependent. Therefore, with average environmental temperatures of Niger Delta between $20^{\circ} \mathrm{C}$ to $28^{\circ} \mathrm{C}$ [9]. This temperature range is obviously far too high when compared to the ISO conditions of temperature, $15^{\circ} \mathrm{C}$ and relative humidity of $60 \%$ [10]. The effects of high environment temperature means the performance of the gas turbine plants are adversely affected.

One effective technology employed to reduce the environmental temperatures is evaporative cooling. According to [11], evaporative cooler is generally becoming more effective where temperatures are high, relative humidity is very low, water is available for the purpose and air is conductive. It is an economical means of reducing temperatures and increasing humidity in an enclosure where the humidity is comparatively low [12].

\section{Evaporative Cooling Methods}

The principle underlying evaporative cooling is the conversion of sensible heat to latent heat with a 
consequent decrease in space temperature as shown in Figure 1 and Figure 2. Basically, evaporative cooling could be achieved either through direct and indirect evaporative Cooling. Direct evaporative cooling (DEC) involves the movement of air through a moist medium where evaporation and cooling occurs. This cool and moist air is then allowed to move directly to where it is needed. Whereas, the indirect evaporative cooling (INDEC) uses some form of heat exchanger that employs the cool, moist air produced through the direct method, to lower the temperature of a drier air. This cool, dry air is in turn used to cool the environment while the cool moist air is expelled.

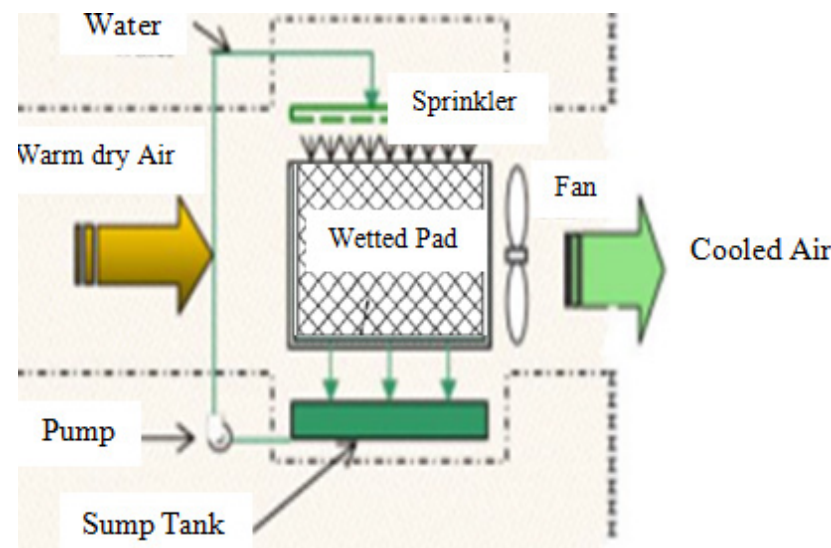

Figure 1. Schematic Diagram of Direct Evaporative Cooler [13]

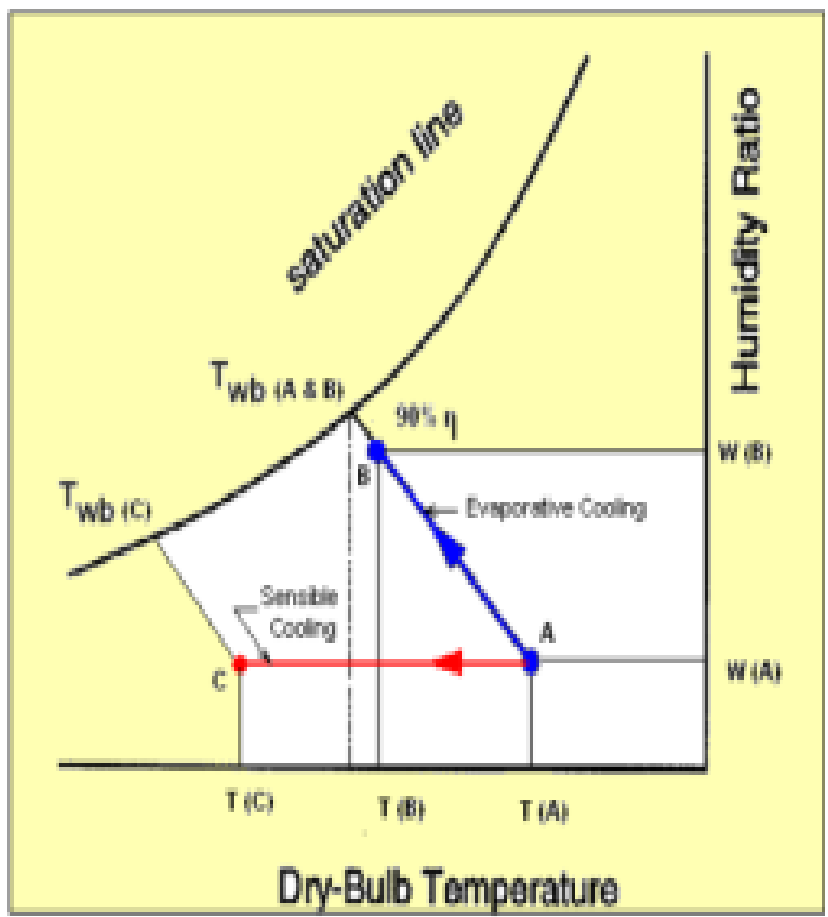

Figure 2. Psychometric Chart Illustrating Evaporative Cooling [16]

The basic components of DEC are: pad, pump, fan and a sump. The pad is made wet with water from the sump tank by a pump which sends water up the top of the pad from where it gradually trickles down. Warm, dry and low humidity outdoor air is drawn with fan through wet filter pad. The pad filters the air of impurities and the water gains sensible heat from the incoming dry air and converts it to latent heat that evaporates the water within the pads.
The dry bulb temperature is reduced, $\mathrm{T}(\mathrm{A})$ to $\mathrm{T}(\mathrm{B})$ while the humidity of the air is increased from $A$ to $B$ as illustrated in Figure 2. The process is considered adiabatic (no heat gain or loss) because sensible heat is converted to latent heat in the added vapour. The latent heat follows the water vapour and diffuses into the air [14]. As long as evaporation takes place, the exit air temperature will be lower than that of the ambient.

However, there are factors that affect the performance of evaporative cooling system which have been determined by several researchers. Among them are environmental conditions (inlet temperature and relative humidity), pad material, pad thickness and density, pad air face velocity and water flow in pads [15]. This research, therefore seeks to investigate the performance of a direct evaporative cooler in a tropical climate as in Niger Delta, Nigeria.

\section{Materials and Methods}

An evaporative cooler was locally constructed as seen in Figure 3. The pad is of cellulose type and is porous enough to allow the flow of air through it. The pad has thickness, t of $0.06 \mathrm{~m}$; Height $(\mathrm{H})$ and width $(\mathrm{W}), 0.48 \mathrm{~m}$ and $0.36 \mathrm{~m}$ respectively. The water distribution system consists of a tank, pipe and overhead tank. Two water tanks were installed, one on the top of the cooler and the other at the bottom. The top tank with square base of side $55 \mathrm{~cm}$, depth of $19 \mathrm{~cm}$ with capacity of 55.475 litres contains water that is fed to the distribution system. Then the collection tank of $75 \mathrm{~cm}$ square cross-section and 14.5 deep at the bottom of the cooler collects excess water from the pad. The fan located in the middle of the wall of cabin opposite the pad end creates a negative pressure inside below that of the atmosphere. This results in inflow of dry air through the wet pad to the cabin where the cooling is required. As the air passed through the wet pad into the cabin, it gave out its sensible heat and get cooled. Part of the water in the wet pad then gained latent heat and evaporates. The location of the fan in the middle ensures that the cool and humid air is uniformly distributed within the cabin. The pad is continuously kept wet by the water trickling on the pad from the water tank through the perforated pipe equipped with stop valve. The bottom tank collects excess water from the pad which is made to circulate through the tank manually.

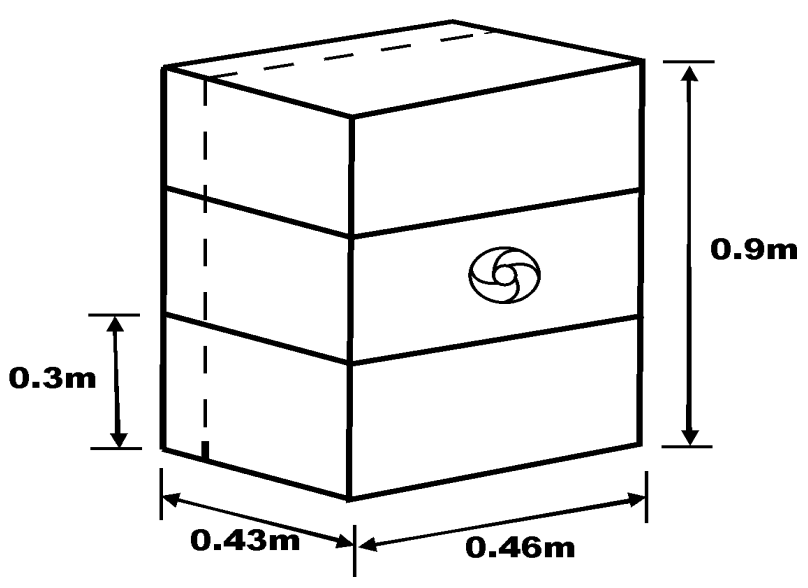

Figure 3. Isometric View of the Cooler 
The study was carried out in the Southern coastal area of Nigeria. Ambient temperatures and relative humidity were taken at particular times. Hence, the properties of dry air $\left(\mathrm{C}_{\mathrm{pa}}, \mathrm{v}\right.$ and $\left.\mathrm{k}\right)$ are based on the ambient temperatures values. The exact values were obtained by interpolation between dry bulb temperatures of $20^{\circ} \mathrm{C}$ and $40^{\circ} \mathrm{C}$

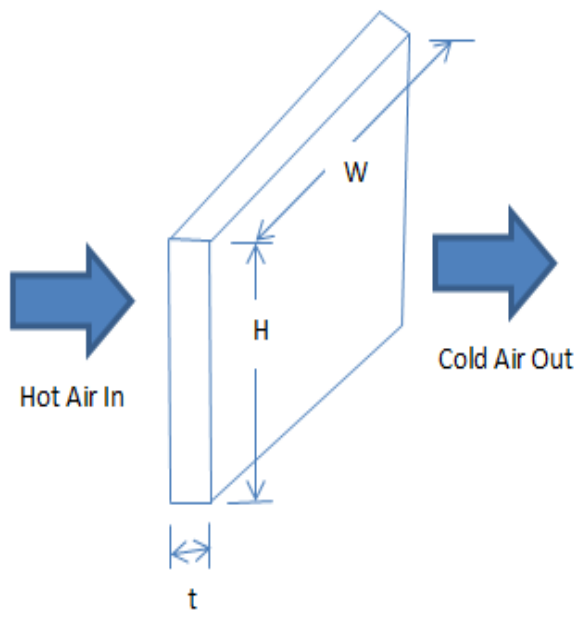

Figure 4. The Rectangular Cellulose pad

\subsection{Performance Evaluation}

One criterion for evaluating the cooling pad is to calculate the cooling efficiency.

The saturation or cooling efficiency of the evaporative pad is calculated as:

$$
\varepsilon=1-\exp \left(-\frac{h_{1} A_{w}}{m_{a} C p_{a}}\right)=\frac{\Delta T}{T_{1}-T_{w}}
$$

Where: $\Delta T$ is the difference between the entering and exit dry-bulb temperatures, $\mathrm{T}_{1}-\mathrm{T}_{2}$.

Feasibility index $\left(\mathrm{F}^{*}\right)$ is defined as:

$$
F^{*}=T_{w}-\left(T_{1}-T_{w}\right) \text {. }
$$

The smaller the $\mathrm{F}^{*}$, the more efficient the evaporative cooling. It indicates the evaporative cooling potential to give thermal comfort. $\left(T_{1}-T_{w}\right)$, wet bulb depression; $T_{l}$ inlet dry bulb temperature; $T_{w}$ wet bulb temperature. The greater the difference between the two temperatures, the greater is the evaporative cooling effect.

According to [14], $F^{*} \leq 10$ for comfort cooling; $11 \leq F^{*} \leq 16$ for relief (lenitive) cooling and for $F^{*}>16$ not recommended for the use of evaporative cooling systems.

Total wetted surface area $(\mathrm{A} w)$ of the rectangular pad is given as:

$$
A_{w}=A_{1} \times H \times W \times t .
$$

According to [17], the outlet air dry bulb temperature can be calculated as:

$$
T_{2}=T_{1}-\varepsilon\left(T_{1}-T_{w}\right) .
$$

The cooling capacity is then given as:

$$
Q=m_{a} C p_{a}\left(T_{1}-T_{2}\right) * 3.6 .
$$

The quantity of water, $\mathrm{Q}_{\mathrm{w}}$ needed (consumption) by the evaporative cooler is calculated from:

$$
\begin{gathered}
Q_{w}=m_{a}\left(\omega_{2}-\omega_{1}\right) \\
m_{\mathrm{a}}=H \times W \times V_{a} \times \rho
\end{gathered}
$$

Where:

$Q=$ cooling capacity $(\mathrm{kJ} / \mathrm{h})$

$m_{\mathrm{a}}=$ air flow rate $(\mathrm{kg} / \mathrm{s})$

$C p_{\mathrm{a}}=$ Specific heat of air $(\mathrm{J} / \mathrm{kgK})$

$V_{\mathrm{a}}=$ velocity of air at inlet of pad $(\mathrm{m} / \mathrm{s})$

$\omega_{2}$ and $\omega_{1}$ are determined from the psychometric chart.

$\boldsymbol{\rho}=$ density of air $\left(\mathrm{kg} / \mathrm{m}^{3}\right)$

$A_{1}=$ Wetted surface area of pad material per unit volume $\mathrm{m}^{2} / \mathrm{m}^{3}$.

$h_{l}=$ Convective heat transfer coefficient $\left(\mathrm{W} / \mathrm{m}^{2} \mathrm{~K}\right)$ can be calculated from the Nusselt number:

$$
h=\frac{N_{u} \times k}{l_{x}}
$$

Where $\mathrm{k}$, thermal conductivity is the property of a material (air) to conduct heat and it is a function of air temperature. The values of $\mathrm{k}$ are determined from the thermal conductivity of air against the corresponding temperature values. $l_{x}$ is known as the characteristic length and according to [18] is given as:

$$
\begin{gathered}
l x=\frac{H \times W \times t}{A_{w}} \\
N_{u}=0.1\left(\frac{l x}{t}\right)^{0.12} R_{e}^{0.8} \operatorname{Pr}^{\frac{1}{3}} .
\end{gathered}
$$

Reynolds number, $\mathrm{R}_{\mathrm{e}}$ is given as:

$$
R_{e}=\frac{V_{a} \times l x}{v}
$$

Where $v$ is the kinematic viscosity and the Prandtl number, Pr is also given as:

$$
\operatorname{Pr}=\frac{v}{a}
$$

Where $a$ is the thermal diffusivity which measures the rate of heat transfer of a material from the hot side to the cold side. It is mathematically expressed as:

$$
a=\frac{k}{\rho \times C_{p a}} m^{2} / s
$$

$\mathrm{T}_{\mathrm{w}}=$ wet bulb temperature $(\mathrm{K})$

$\mathrm{H}=$ height of pad

$\mathrm{W}=$ width of pad

$\mathrm{t}=$ thickness of pad

$\mathrm{k}=$ thermal conductivity $(\mathrm{W} /(\mathrm{m} \cdot \mathrm{K})$

Table 1. Values of Parameters used in Calculation

\begin{tabular}{|c|c|}
\hline Parameters & Units \\
\hline $\mathrm{A}_{1}$ & $220 \mathrm{~m}^{2} / \mathrm{m}^{3}$ \\
\hline $\mathrm{t}$ & $0.06 \mathrm{~m}$ \\
\hline $\mathrm{H}$ & $0.48 \mathrm{~m}$ \\
\hline $\mathrm{W}$ & $0.36 \mathrm{~m}$ \\
\hline$V_{a}$ & $4.0 \mathrm{~m} / \mathrm{s}$ \\
\hline$A_{w}$ & $3.04 \mathrm{~m}^{2}$ \\
\hline$l x$ & $0.00455 \mathrm{~m}$ \\
\hline $\mathrm{m}_{\mathrm{a}}$ & $0.69 \rho \mathrm{kg} / \mathrm{s}$ \\
\hline
\end{tabular}




\section{Result and Discussion}

The constructed system was tested in order to assess its performance. Some parameters namely temperatures (dry bulb inlet, wet bulb and dry bulb outlet), saturation efficiency, capacity of the cooler and feasibility index were of particular interest. The daily readings of temperatures (dry and wet bulbs) and relative humidity of air measured at hourly intervals and these are shown in Table 3. Thereafter, Table 3 was generated with data from Table 2 and Table 3. Values for $\mathrm{F}^{*}, \varepsilon, \mathrm{T}_{2}$ and $\mathrm{Q}$ were calculated and tabulated. The calculation was made simpler by $\mathrm{C}++$ and Microsoft excel.
Table 2. Temperature and Relative Humidity Readings with Time (Hrs.)

\begin{tabular}{|c|c|c|c|}
\hline Time & \multicolumn{3}{|c|}{ Ambient Condition } \\
\hline (Hrs.) & $\mathrm{T}_{1}\left({ }^{\circ} \mathrm{C}\right)$ & $\left.\mathrm{T}_{\mathrm{w}}{ }^{0} \mathrm{C}\right)$ & $\mathrm{RH}(\%)$ \\
\hline 8 & 26 & 22 & 69 \\
\hline 9 & 28 & 22 & 60 \\
\hline 10 & 29 & 22.5 & 55 \\
\hline 11 & 31 & 23 & 48 \\
\hline 12 & 32 & 22.5 & 41 \\
\hline 13 & 33 & 22 & 35 \\
\hline 14 & 34 & 22 & 32 \\
\hline 15 & 32 & 22 & 35 \\
\hline 16 & 33 & 22 & 39 \\
\hline 17 & 32 & 20.5 & 39 \\
\hline 18 & 29 & 21 & 46 \\
\hline
\end{tabular}

Table 3. Calculated properties of air on hourly inte

\begin{tabular}{|c|c|c|c|c|c|c|c|c|c|c|c|}
\hline Time (Hrs) & \multicolumn{3}{|c|}{ Ambient Condition } & \multirow[b]{2}{*}{$\rho\left(\mathrm{Kg} / \mathrm{m}^{3}\right)$} & \multirow[b]{2}{*}{$\mathrm{m}_{\mathrm{a}}(\mathrm{kg} / \mathrm{s})$} & \multirow[b]{2}{*}{$\mathrm{Cp}_{\mathrm{a}}(\mathrm{kJ} / \mathrm{kgK})$} & \multirow[b]{2}{*}{$\mathrm{k}(\mathrm{W} / \mathrm{mK})$} & \multirow[b]{2}{*}{$v^{*} 10^{6}\left(\mathrm{~m}^{2} / \mathrm{s}\right.$} & \multirow[b]{2}{*}{$\mathrm{a}$} & \multirow[b]{2}{*}{$\mathrm{Re}$} & \\
\hline $\mathrm{t}$ & $\mathrm{T}_{1}\left({ }^{\circ} \mathrm{C}\right)$ & $\mathrm{Tw}\left({ }^{\circ} \mathrm{C}\right)$ & RH (\%) & & & & & & & & \\
\hline 8 & 26 & 22 & 69 & 1.182 & 0.815 & 1.005 & 0.026 & 15.67 & 0.022 & 1161.60 & \\
\hline 9 & 28 & 22 & 60 & 1.174 & 0.81 & 1.005 & 0.026 & 15.67 & 0.022 & 1148.84 & \\
\hline 10 & 29 & 23 & 55 & 1.170 & 0.807 & 1.005 & 0.026 & 15.67 & 0.023 & 1148.84 & \\
\hline 11 & 31 & 23 & 48 & 1.162 & 0.802 & 1.005 & 0.026 & 15.67 & 0.023 & 1148.84 & \\
\hline 12 & 32 & 23 & 41 & 1.158 & 0.799 & 1.005 & 0.027 & 15.67 & 0.023 & 1148.84 & \\
\hline 13 & 33 & 22 & 35 & 1.154 & 0.796 & 1.005 & 0.027 & 15.67 & 0.023 & 1148.84 & \\
\hline 14 & 34 & 22 & 32 & 1.150 & 0.794 & 1.005 & 0.027 & 15.67 & 0.023 & 1148.84 & \\
\hline 15 & 32 & 22 & 35 & 1.158 & 0.799 & 1.005 & 0.027 & 15.67 & 0.023 & 1148.84 & \\
\hline 16 & 33 & 22 & 39 & 1.154 & 0.796 & 1.005 & 0.027 & 15.67 & 0.023 & 1148.84 & \\
\hline 17 & 32 & 21 & 39 & 1.158 & 0.799 & 1.005 & 0.027 & 15.67 & 0.023 & 1148.84 & \\
\hline 18 & 29 & 21 & 46 & 1.170 & 0.807 & 1.005 & 0.026 & 15.67 & 0.023 & 1148.84 & \\
\hline Time (Hrs) & $\mathrm{Aml}$ & ondition & & & & & & & & & \\
\hline $\mathrm{t}$ & $\mathrm{T}_{1}\left({ }^{\circ} \mathrm{C}\right)$ & $\mathrm{Tw}\left({ }^{\circ} \mathrm{C}\right)$ & RH (\%) & $\operatorname{Pr}$ & $\mathrm{Nu}$ & $\mathrm{h}$ & $\mathrm{F}^{*}$ & $\varepsilon$ & $\mathrm{T}_{2}\left({ }^{\circ} \mathrm{C}\right)$ & $\mathrm{T}_{1}-\mathrm{T}_{2}\left({ }^{\circ} \mathrm{C}\right)$ & $\mathrm{Q}(\mathrm{kJ} / \mathrm{h})$ \\
\hline 8 & 26 & 22 & 69 & 0.71 & 18.58 & 106.70 & 18 & 0.583 & 23.67 & 2.33 & 1.91 \\
\hline 9 & 28 & 22 & 60 & 0.71 & 17.82 & 102.80 & 16 & 0.585 & 24.49 & 3.51 & 2.86 \\
\hline 10 & 29 & 23 & 55 & 0.71 & 17.82 & 103.10 & 16 & 0.586 & 25.19 & 3.81 & 3.09 \\
\hline 11 & 31 & 23 & 48 & 0.71 & 17.81 & 103.60 & 15 & 0.589 & 26.29 & 4.71 & 3.80 \\
\hline 12 & 32 & 23 & 41 & 0.71 & 17.81 & 103.90 & 13 & 0.59 & 26.40 & 5.60 & 4.50 \\
\hline 13 & 33 & 22 & 35 & 0.71 & 17.81 & 104.20 & 11 & 0.591 & 26.50 & 6.50 & 5.21 \\
\hline 14 & 34 & 22 & 32 & 0.71 & 17.81 & 104.40 & 10 & 0.592 & 26.89 & 7.11 & 5.67 \\
\hline 15 & 32 & 22 & 35 & 0.71 & 17.81 & 103.90 & 12 & 0.590 & 26.10 & 5.90 & 4.74 \\
\hline 16 & 33 & 22 & 39 & 0.71 & 17.81 & 104.20 & 11 & 0.591 & 26.50 & 6.50 & 5.21 \\
\hline 17 & 32 & 21 & 39 & 0.71 & 17.81 & 103.90 & 9 & 0.590 & 25.22 & 6.78 & 5.45 \\
\hline 18 & 29 & 21 & 46 & 0.71 & 17.82 & 103.10 & 13 & 0.586 & 24.31 & 4.69 & 3.80 \\
\hline
\end{tabular}

\section{Discussion}

Figure 5 shows a graph of the cooler capacity against the exit dry bulb temperature. From the graph, it is obvious that the cooler capacity rises as the exit dry bulb temperature increases and decreases with it. The graph shows that at the maximum $\mathrm{Q}, \mathrm{T}_{1}-\mathrm{T}_{2}$ is higher and $\mathrm{F}^{*}$ is 9 .

Figure 6 is a graph that illustrates the performance of saturation efficiency with the time. The performance of an evaporative cooler is assessed by the saturation efficiency. Numerous researches had proven that saturation efficiency of commonly used cooling pad materials fall within $50 \%$ to $90 \%$ [19]. Figure 6 shows that the efficiency is within the range peaking at $59 \%$.

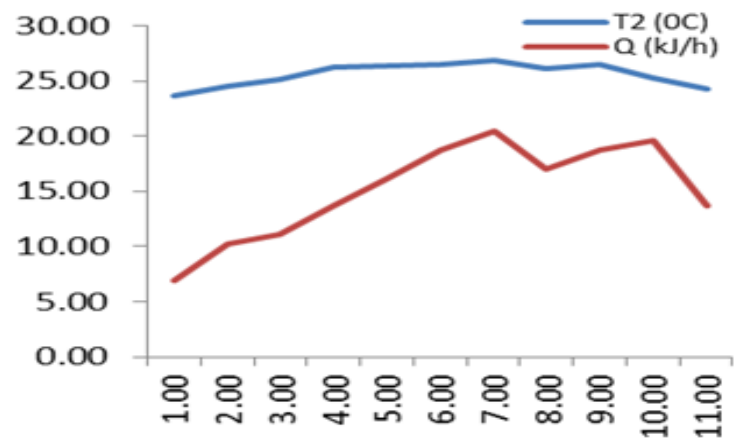

Figure 5. Illustration of Cooler Capacity, $\mathrm{Q}(\mathrm{kJ} / \mathrm{h})$ with Exit Dry Bulb Temperature, $\mathrm{T}_{2}\left({ }^{0} \mathrm{C}\right)$ 


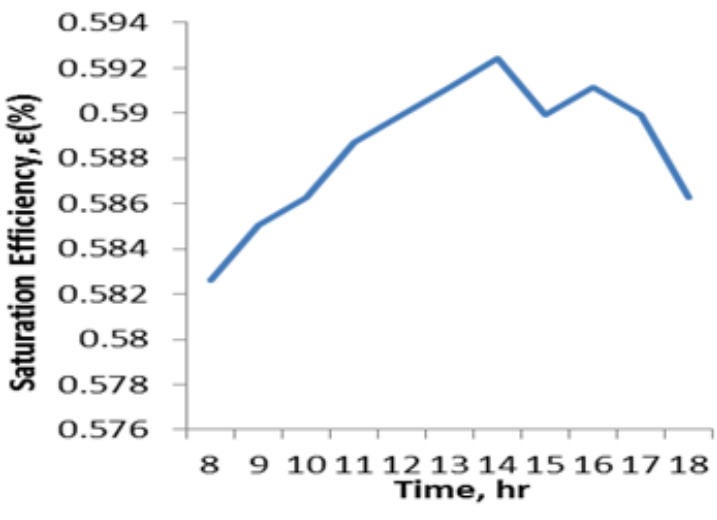

Figure 6. Saturation Efficiency against Time

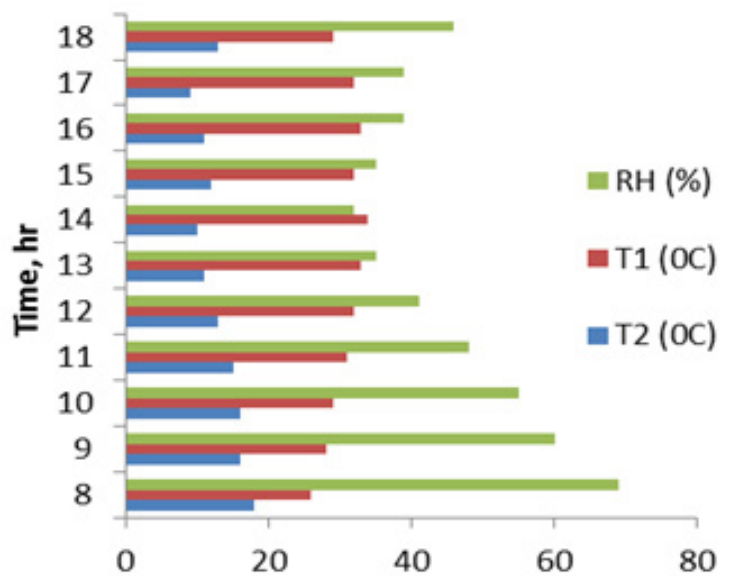

Figure 7. The Effects of time of the day on $\mathrm{RH}, \mathrm{T}_{1}$ and $\mathrm{T}_{2}$

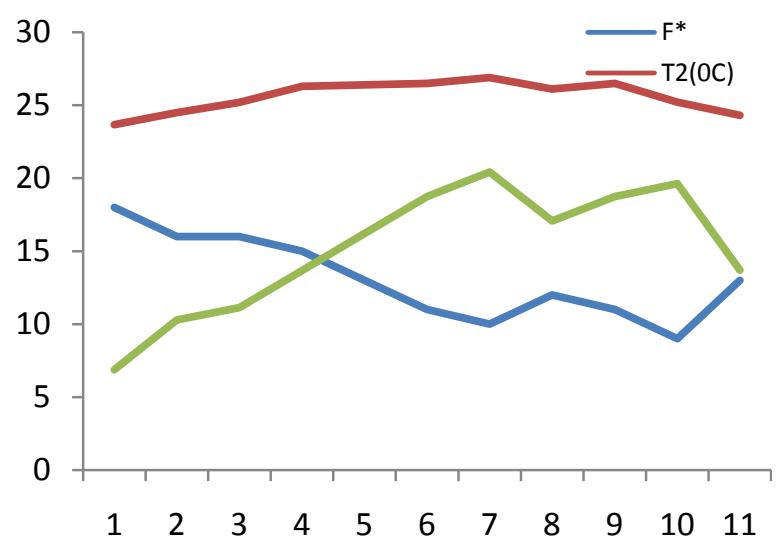

Figure 8. Relationship between Feasibility Index, Cooler Capacity and Exit Temperature

The bars in Figure 7 depict the inlet dry bulb temperature, relative humidity of the inlet air and the exit dry bulb temperature with the hourly readings. From Figure 7, it can be seen that though at the lowest inlet and exit dry bulb temperatures, the humidity of inlet air is higher at 08:00 a.m. However, at this time Table 3 shows that cooler capacity was the least and the value of $\mathrm{F}^{*}$ is 18 . This shows that with, high relative humidity and low $\mathrm{T}_{1}-\mathrm{T}_{\mathrm{w}}$ and $\mathrm{T}_{1}-\mathrm{T}_{2}$, evaporative cooling is not feasible.

Figure 8 shows the relationship between feasibility index, $\mathrm{F}^{*}$, exit temperature, $\mathrm{T}_{2}$, cooler capacity, Q. Thorough observation of Figure 8 and Table 2 shows that $\mathrm{F}^{*}$ of 9 and 10 gives the highest saturation efficiency and cooler capacity. Also, it can be observed that at these points both $T_{1}-T_{2}$ and $T_{1}-T_{w}$ give the greatest values.

\section{Conclusion}

The objective of this work is to investigate the performance of an evaporative cooler with a specified pad thickness in Niger Delta area of Nigeria. Parameters for the performance assessment were saturation efficiency, cooler capacity, feasibility index and the exit temperature. It can be seen from the daily readings when the inlet dry bulb temperature is lowest early in the morning $(8: 00 \mathrm{hrs}), \mathrm{F}^{*}$ is maximum, 18 and with the two maximum temperatures of $34^{\circ} \mathrm{C}$ and $32^{\circ} \mathrm{C}$, the $\mathrm{F}^{*}$ falls within the range of $F^{*} \leq 10$. The results showed that evaporative cooling is most efficient in periods of high ambient temperatures. And that the greater the difference between $T_{1}$ and $T_{w}$, the greater the evaporative cooling effects.

\section{Acknowledgements}

We humbly wish to acknowledge $\mathrm{Mr}$ Canaan, Ayibakarelayefa for the insight, motivation and for providing the relevant materials needed for this work.

\section{References}

[1] Ndukwu, M. C., Manuwa, S. I., Olukunle, O. J. and Oluwalana, I. B. (2013) Mathematical Model for Direct Evaporative Space Cooling Systems. Nigerian Journal of Technology (NIJOTECH) Vol. 32. No. 3. pp. 403-409.

[2] Kulkarni, R. K., Rajput, S. P. S., Gutte, S. A. and Patil, D. M. (2014) Laboratory Performance Of Evaporative Cooler Using Jute Fiber Ropes As Cooling Media. International Journal of Engineering Research and Applications, Vol. 4, Issue 12, pp. 60-66.

[3] Dodoo, A., Gustavsson, L. and Sathre, L. (2011) "Building Energy-efficiency Standards in a Life Cycle Primary Energy Perspective," Energy and Buildings, Vol. 43, No. 7, pp. 1589-1597.

[4] Foster, R. E. (2013) Evaporative Air-Conditioning Contributions to Reducing GreenhouseGas Emissions and Global Warming. Retrieved 10 February, 2017 from the World Wide Web: http://citeseerx.ist.psu.edu/viewdoc/download?doi=10.1.1.576.710 $7 \&$ rep $=$ rep $1 \&$ type $=p d f$.

[5] Sanchez-Mata (2003) New Recommendation for Building in Tropical Climates, Building and Environment. Vol. 28, pp. 271-278.

[6] Liberty J. T; Okonkwo W. I. and Echiegu E. A. (2013). Evaporative Cooling: A Postharvest Technology for Fruits and Vegetables Preservation. International Journal of Scientific and Engineering Research, Vol. 4, Issue 8, 2257-2266.

[7] Susan, D. S. and Durward S. (1995) G95-1264 Storing Fresh Fruits and Vegetables. Historical Materials from University of Nebraska-Lincoln Extension. Retrieved 8 February, 2017 from the World Wide Web: http://digital commons.unl.edu/extensionhist/1042/.

[8] Lerner, B. R., and Dana, M. N. (2001) Storing Vegetables and Fruits at Home, Purdue University Cooperative Extension Service, West Lafayette, Retrieved 12 January, 2017 from the World Wide Web: http://www.hort.purdue.edu/ext/ho 125.pdf.

[9] Poku, R., Ogbonnaya, E. A. and Oyinki, W. T. (2015) ThermoEconomic Analysis of Evaporative Cooling in a Gas Turbine Plant in Niger Delta, Nigeria. OSR Journal of Engineering (IOSRJEN), Vol. 05, Issue 03: pp. 59-69.

[10] Cengel and Boles (2006) Thermodynamic: An Engineering Approach; $5^{\text {Th }}$ Edition, McGraw -Hill Companies , Inc., 1221 advance of Americans, New York 10020, pp. 584. 
[11] Rusten, E. (1985) Understanding Evaporative Cooling, Volunteers in Technical Assistance. Technical Paper \#35. VITA, Virginia, USA.

[12] Sushmita, M.D., Hemant, D., and Radhacharan, V. (2008) Vegetables in Evaporative Cool Chamber and in Ambient, Macmillan Publi. Ltd., London and Basingstoke, pp. 1-10.

[13] Xuan, Y. M., Xiao, F., Niu, X. F., Huang, X. and Wang, S. W. (2012) Research and Application of Evaporative Cooling in China: A Review (I)-Research. Renewable and Sustainable Energy Reviews, Elsevier. Issue 16, pp. 3535-3546.

[14] Watt, J. R. (1963) Evaporative air conditioning. New York: The Industrial Press, p.300.

[15] Ndukwu, M. C. and Manuwa, S. I. (2014) Review of Research and Application of Evaporative Cooling In Preservation of Fresh
Agricultural Produce. Int J Agric \& Biol Eng. Vol. 7, No.5: pp. 85-102.

[16] Bhatia, A. (2012) Principles of Evaporative Cooling System. Retrieved 13 January, 2017 from the World Wide Web: file://C:/Users/ROBERT/AppData/Local/Temp/m231 content.pdf.

[17] Watt, R. J. and Brown, W. K. (1994) Evaporative Air Conditioning Hand Book, $3^{\text {rd }}$ edn(The Fairmane Press Inc, Liburn GA). pp.185-189.

[18] Camargo, J. R., Ebinuma, C. D. and Cardoso, S. A. (2003) Mathematical Model for Direct Evaporative Cooling Air Conditioning System. Engenharia Térmica, Curitiba, Vol. 04, p. 30-34.

[19] Kulkarni, R. K. and Rajput, S. P. S. (2011) "Comparative Performance of Evaporative Cooling pads of alternative Materials". International Journal of Advanced Engineering Sciences and Technologies, Vol. 10, Issue 2, pp 239-244. 